\title{
Preschool Participation and BMI at Kindergarten Entry: The Case for Early Behavioral Intervention
}

\author{
Meghan E. McGrady, ${ }^{1}$ Monica J. Mitchell, ${ }^{2}$ Sarah N. Theodore, ${ }^{2}$ Brian Sersion, ${ }^{3}$ \\ and Elizabeth Holtzapple ${ }^{3}$ \\ ${ }^{1}$ Department of Psychology, University of Cincinnati, 4150 Edwards Building One, P.O. Box 210376, \\ Cincinnati, OH 45221-0376, USA \\ ${ }^{2}$ Division of Behavioral Medicine and Clinical Bychology, Cincinnati Children's Hospital Medical Center, \\ 3333 Burnet Avenue, Cincinnati, OH 45229, USA \\ ${ }^{3}$ Cincinnati Public Schools, P.O. Box 5381, Cincinnati, OH 45201-5381, USA
}

Correspondence should be addressed to Meghan E. McGrady, mcgradmn@mail.uc.edu

Received 15 September 2009; Revised 21 January 2010; Accepted 23 March 2010

Academic Editor: David B. Allison

Copyright (C) 2010 Meghan E. McGrady et al. This is an open access article distributed under the Creative Commons Attribution License, which permits unrestricted use, distribution, and reproduction in any medium, provided the original work is properly cited.

\begin{abstract}
Preschool years (ages 3-5) are a critical period in growth and development. Emerging studies suggest that preschool attendance may be linked to future weight, and perhaps obesity. This study examined relationships between public preschool attendance, demographic variables, and weight at kindergarten entry. Participants included 2,400 children entering kindergarten in 2006. Height and weight were used to calculate a child's BMI category based on CDC norms. At kindergarten entry, 17\% of participants were overweight, and $18 \%$ were obese. Children attending a public preschool were at an increased risk for overweight $(\mathrm{OR}=1.06)$ and obesity $(\mathrm{OR}=1.34)$ at kindergarten entry, $\chi^{2}(2)=6.81, P=.03$ relative to children who did not attend preschool. No significant trends relationships between demographics and weight status were found, but demographic variables are summarized descriptively. Policy and clinical implications are provided.
\end{abstract}

\section{Introduction}

Over a third of U.S. children are overweight or obese, a drastic increase from $16 \%$ in 1974 [1]. Overweight or obese children (those with a body mass index for age at or above the 85th percentile based on Centers for Disease Control and Prevention norms) are at an increased risk for cardiovascular, metabolic, pulmonary, gastrointestinal, and skeletal complications [2]. Overweight and obese children are also more likely to experience psychosocial difficulties such as depressive symptoms and impairments in healthrelated quality of life than their nonoverweight peers [3-5].

Between the ages of three and five, adiposity rebound occurs, and children develop the eating and physical activity behaviors that will influence their lifetime habits [6-8]. As a result, the preschool years (ages 3-5 years) have been identified as a critical period in growth and obesity development. The development of childhood obesity is commonly conceptualized within an ecological framework in which family, community and social factors, social policies, and national legislation may impact a child's weight status [9]. Within this model, child and family characteristics such as minority race and low socioeconomic status may serve as high-risk factors for obesity [9].

Community-level factors that further contribute to weight status include neighborhood factors such as childcare attendance [9]. It is estimated that $63 \%$ of children in the US under the age of five receive care outside of the home [10]. Given the large percentage of children attending preschool and the fact that the preschool environment can influence food intake and physical activity levels [9], it is important to examine the relationship between the preschool environment and weight status during this period.

Currently, research is limited and studies examining this link remain inconclusive. Results of a study of 1,244 grade school children indicated that limited child care attendance 
( $0-15$ hours of child care a week during ages $3-5$ years) was related to a decreased risk of being overweight in grade school (ages 6-12 years) [11]. Contrary to their hypothesis, researchers found no significant association between extensive child care attendance ( $>15$ hours per week) and weight status in grade school [11].

To our knowledge, the only other study to examine this relationship and the only study to specifically examine preschool attendance was conducted by Maher et al. [12]. Using data obtained from participants in the Early Childhood Longitudinal Study-Kindergarten Cohort (ECLS$\mathrm{K})$, researchers tested the relationship between child care participation in the year prior to kindergarten entry and BMI $z$-scores at kindergarten entry. Results indicated that non-Latino children attending Head Start were more likely to be obese at kindergarten entry than non-Latino children receiving home-based parent care, regardless of family income [12].

Given the inconclusive state of the literature, the purpose of the current study was to examine the relationship between preschool attendance (at ages 3-5 years) and obesity at kindergarten entry in a sample of urban children (ages 5-6 years). Results of this study will further our understanding of the relationship between preschool attendance and future weight. Particularly, this study will provide additional information regarding this relationship in an exclusively urban population, which has not yet been examined. This increased understanding will facilitate the development of a more accurate empirically based model of obesity development and could provide support for improvements to public policy.

The primary aim of this study was to examine the relationships between income, race/ethnicity, and preschool attendance and weight status at kindergarten entry in a sample of urban children. Based on an ecological framework model, it was hypothesized that lower family income, minority status, and preschool attendance would be linked to overweight or obesity at kindergarten entry.

\section{Method}

2.1. Participants. The data for this study are part of the database created for an assessment of kindergarten readiness. The larger database is maintained by a Midwestern, urban, public school district and includes information regarding all students attending the public school district at the time of kindergarten entry, as well as retrospective data.

Data for this study were collected in fall 2006 from all children entering kindergartens in a Midwestern, urban, public school district in the US for the 2006-2007 academic year. From this sample, the 2,534 participants (ages 5-6 years) with height and weight measurements were included. Since the purpose of this study was to examine the relationship between attendance at a public preschool and BMI at kindergarten entry, the 120 individuals who attended private preschools were excluded from the analysis, resulting in a usable sample of 2,414 participants.

2.2. Data Collection. Data were collected as part of a health screen administered by school nurses in accordance with the National School Health guidelines. Prior to measurement, parent consent was obtained by the school district. Consistent with standard district procedures, kindergarten children were weighed and measured by school nurses within the first 60 days of the school year. Measurements were entered according to identification numbers, and thus deidentified. Data were then included as part of a larger public dataset managed by the city's Health Department nurses. At kindergarten entry, caregivers provided demographic and background information to the school district. This information was included in a de-identified database supplied by the district, and then included in the analysis. The analysis and reporting of this data was approved by the site's Institutional Review Board.

2.3. Dependent Variable: BMI Category. Height was measured using a standing height board or a stadiometer, and recorded to the nearest $0.25 \mathrm{in}$. Weight was measured using a calibrated platform balance beam scale or medical grade digital scale on an uncarpeted floor, and recorded to the nearest $0.25 \mathrm{lb}$. These data were used to calculate age and gender-specific BMI-for-age percentiles (hereafter referred to as BMI) for each child according to the Centers for Disease Control and Prevention (CDC) BMI charts [13]. Participants were categorized as underweight $(<5$ th percentile), normal weight (5th-84th percentiles), overweight (85th95 th percentiles), and obese ( $\geq 95$ th percentile). For data analytic purposes, these categories were collapsed into the following three categories: underweight and normal weight, overweight, and obese.

2.4. Independent Variables. Demographic variables selected for the purposes of these analyses included age, gender, race/ethnicity, lunch status, and preschool attendance. Based on the composition of the sample and the assumptions of logistic regression, race/ethnicity was simplified to four categories: African-American, White (Hispanic), White (nonHispanic), or other race. Family income was measured as a dichotomous variable indicating whether or not the child received free or reduced-price lunch. Children receive free lunch or reduced-price lunch if the income of their household is less than $130 \%$ or $185 \%$ of the poverty line, respectively. The preschool attendance variable was a dichotomous indicator of whether or not the child had attended a public preschool and given the limitations of our database, did not take into account the number of years of attendance or the type of public preschool (i.e., Head Start versus other).

2.5. Data Analysis. Descriptive statistics including means and standard deviations were calculated for the entire sample, and by weight category.

Multinomial logistic regression models were used to examine variables that predicted weight category at kindergarten entry, controlling for demographic characteristics. For the purpose of our analyses, weight categories (as defined by the CDC norms) were collapsed to yield the following categories: normal-weight ( $<85$ th percentile), overweight (85th95 th percentiles), and obese ( $\geq 95$ th percentile). Exploratory 
analyses revealed that $14(<1 \%)$ of participants had BMI percentages likely due to measurement error $(<1 \%)$, and thus were excluded from the analyses, resulting in a final sample of 2,400 children. The initial model included preschool attendance, race/ethnicity, family income, gender, and all possible interaction terms and used "normal weight children" as the reference category. Given the empirical support for all predictor variables, backwards elimination was used until only variables and interactions significant at the 0.05 level remained (using the $\chi^{2}$ selection test). Akaike information criteria were used to compare the fit of the initial model and the final model. All analyses were conducted using Predictive Analytics Software Statistics 18 (PASW).

\section{Results}

Descriptive statistics for the entire sample as well as by weight status are presented in Table 1 . The average age of participants was 5 years and 7 months ( $S D=5$ months). Participants were primarily male (52\%) and African-American (64\%). In all, $56 \%$ of participants had attended at least one year of preschool, and $73 \%$ were receiving free or reduced-price lunch. Preschool attendance was significantly related to family income, $\chi^{2}(1,2400)=38.67, P=.00$. At kindergarten entry, $18 \%$ of participants were obese, and $17 \%$ were overweight.

The final model included only preschool attendance, and was statistically reliable in distinguishing between normal weight, overweight, and obese children, $\chi^{2}(2)=6.81, P=$ .03 , pseudo $R^{2}=.01$. Examination of Akaike information criteria (AIC) indicated that the final model $($ AIC $=273.50)$ had a better fit to the data than the main effects model $(\mathrm{AIC}=283.56)$. Children attending a public preschool were at an increased risk for overweight $(\mathrm{OR}=1.06 ; 95 \% \mathrm{CI}$ $=0.96-1.16)$ and obesity $(\mathrm{OR}=1.34 ; 95 \% \mathrm{CI}=1.21-$ 1.47) at kindergarten entry relative to children who did not attend preschool. Income, race/ethnicity, and gender were not significant predictors of weight category, and thus were not included in the final model.

\section{Discussion}

A third of the children in our sample were overweight or obese at kindergarten entry (ages 5-6 years). Rates from the current study were markedly higher than CDC norms which define obesity as the 95th percentile or higher (marking $5 \%$ of children in this category) and overweight as the 85th to 94th percentiles (marking 10\% of children in this category) [13]. However, the findings from the current study were slightly higher, but similar to a recently published study with a U.S. nationally representative sample suggesting that $14 \%$ of children between the ages of 2 and 5 years are obese and $12 \%$ are overweight [1]. The findings from the current study are also consistent with national trends showing increases in the percentages of young children who are overweight and obese in recent years [1]. Based on previous research examining BMI trajectories and the percentages of overweight/obesity in this study, it is predicted that, by fifth grade, approximately half of this sample will likely be overweight or obese [14].

The primary aim of this study was to examine predictors of weight category at kindergarten entry. Race/ethnicity was not significantly related to the risk of overweight or obesity at kindergarten entry. While the results are contrary to the hypothesis of race/ethnicity as a risk factor for obesity, confounding variables such as income, home environment, and neighborhood may better account for this effect $[15,16]$. Because the current sample was comprised primarily of children from low-income, urban households in the U.S., the lack of a significant relationship between race/ethnicity and weight category is as expected. Second, the risk of being overweight or obese did not differ based on the child's income. While the results of this study do not support an income effect on obesity status, this may be due to the quality of lunch status as a proxy measure used to indicate income, as lunch status was calculated as a dichotomous variable with significant ranges within both categories.

Consistent with our hypothesis, children who attended a public preschool for at least one year were at an increased risk for being overweight or obese at kindergarten entry. Given the nature of our data, it is not possible to infer causality. However, previous literature suggests that this relationship may be partially due to increased caloric intake and decreased levels of physical activity in preschool settings [9].

One possible explanation may be that children attending public preschools are less active than their peers receiving care in an alternative setting. Studies have indicated that the specific preschool a child attends predicts levels of physical activity [17]. Specifically, children attending Head Start preschools exhibit significantly lower levels of motor activity (as measured by an activity monitor) than their peers attending University preschools [18]. These differences in motor activity may be attributable to the physical environments available to both groups, as the physical space allotted to University preschool classrooms and playgrounds is roughly double that of Head Start classrooms and playgrounds [18].

A second plausible explanation for these findings is that children attending public preschools are consuming more calories than necessary. School lunch programs have helped to meet the nutritional needs of millions of children from low-income families and subsequently protect against dietary deficiency diseases [19]. Recent findings suggest that $85 \%$ of schools serve meals that provide many essential nutrients and meet dietary guidelines for protein, vitamin A, vitamin C, calcium, and iron [19]. Despite significant advances in the quality of school meals, results of the same study suggest that only $6 \%$ of schools offer lunches that meet all criteria. The majority of schools exceed recommendations for saturated fat, and many high-fat meal options are available to students $[20,21]$. Specific characteristics of school meals (i.e., schools where french fries are offered more than once a week) have been related to increased likelihood of obesity [19]. As a result, certain menu-planning practices may help explain the relationship between preschool attendance and weight status documented in this study. 
TABLE 1: Demographics by weight category.

\begin{tabular}{|c|c|c|c|}
\hline & $\begin{array}{l}\text { Underweight or Normal Weight } \\
\quad(<85 \text { th percentiles })\end{array}$ & Overweight (85th-94th percentile) & Obese ( $\geq 95$ th percentile) \\
\hline & $N=1572$ & $N=422$ & $N=406$ \\
\hline \multicolumn{4}{|l|}{ Gender } \\
\hline Male, $N(\%)$ & $810(65 \%)$ & $205(17 \%)$ & $225(18 \%)$ \\
\hline Female, $N(\%)$ & $762(66 \%)$ & $217(19 \%)$ & $181(16 \%)$ \\
\hline \multicolumn{4}{|l|}{ Race/Ethnicity } \\
\hline $\begin{array}{c}\text { African-American } \\
\text { (non-Hispanic), N (\%) }\end{array}$ & $1013(66 \%)$ & $259(17 \%)$ & $258(17 \%)$ \\
\hline White (Hispanic), N (\%) & $38(61 \%)$ & $8(13 \%)$ & $16(26 \%)$ \\
\hline White (non-Hispanic), $N(\%)$ & $426(65 \%)$ & $125(19 \%)$ & $104(16 \%)$ \\
\hline Other, $N(\%)$ & $95(62 \%)$ & $30(20 \%)$ & $28(18 \%)$ \\
\hline \multicolumn{4}{|l|}{ Family Income } \\
\hline $\begin{array}{l}\text { Received Free or Reduced-Price } \\
\text { Lunch, } N(\%)\end{array}$ & $1153(66 \%)$ & $306(17 \%)$ & $301(17 \%)$ \\
\hline $\begin{array}{c}\text { Did Not Receive Free or } \\
\text { Reduced-Price Lunch, N (\%) }\end{array}$ & $419(66 \%)$ & $116(18 \%)$ & $105(16 \%)$ \\
\hline \multicolumn{4}{|l|}{ Preschool Attendance } \\
\hline Attended Preschool, $N(\%)$ & $859(64 \%)$ & $237(18 \%)$ & $151(19 \%)$ \\
\hline $\begin{array}{l}\text { Did Not Attend Preschool, } N \\
(\%)\end{array}$ & $713(68 \%)$ & $185(18 \%)$ & $155(15 \%)$ \\
\hline
\end{tabular}

\section{School and Public Policy Implications}

5.1. Physical Activity. Despite guidelines released by the U.S. National Association for Sport and Physical Education (NASPE) for physical activity, there are no U.S. federal regulations mandating any amount, frequency, or type of physical activity in public preschools [22]. Policies further detailing these components would help to ensure that preschoolers are engaging in levels of physical activity in accordance with these guidelines. In the absence of federal guidelines, school administration could work with classroom teachers to ensure that preschoolers are engaging in the recommended amount of physical activity.

5.2. Nutrition Guidelines. States could also take steps to ensure that children are served well-balanced healthy meals. Current mandates include numerous guidelines regarding fat, sodium, cholesterol, and calories, but menus could be improved. Results from the third School Nutrition and Dietary Assessment Study indicate that $42 \%$ of schools did not offer fresh fruits and vegetables daily, and less than $5 \%$ of breads served are from whole grains [20]. While school meals have improved in recent years, Story [20, p. S12] suggests that "schools need to do even more to reduce the availability of high-calorie, low-nutrient foods and make school meals more nutritious." However, many public schools are not able to provide optimally nutritious meals due to limited funds [20]. Thus, consistent with recommendations from the third School Nutrition and Dietary Assessment Study, reimbursement rates should be reconsidered and additional sources of funding should be explored [20].
5.3. Communication. Because maintaining a healthy weight depends on the school as well as home environment, enhanced parent-teacher communication could lead to improved outcomes. Currently, as recommended by the American Dietetic Association, preschools post menus online and provide hard copies to caregivers [22]. However, recent findings indicate that less than $4 \%$ of these menus are an accurate depiction of what children eat during the school day [23]. This inaccuracy and lack of communication may result in caregivers providing children with more calories than necessary at home. For the current sample as well as most children attending public preschools, parent drop-off and pick-up is required, presenting an ideal opportunity for communication. Given this daily interaction, teachers could communicate to parents the types as well as the quantity of foods consumed by children. Parent teacher conferences typically occur twice a year and present an additional opportunity for communication regarding a child's nutritional needs. As there are no federal or state mandates requiring communication, schools should take the steps necessary to ensure that this communication occurs. In addition, the effectiveness of this communication may be further increased if teachers are provided specialized training regarding appropriate nutrition for preschoolers.

5.4. Caregiver Education. Even with adequate communication, more than half of caregivers do not have the nutrition knowledge necessary to prepare meals that take into account the child's caloric intake in child care [24]. As a result, in accordance with the guidelines suggested by the American Dietetic Association, nutrition education for children and 
their caregivers should be incorporated into child care programs [24].

\section{Clinical Implications}

In addition to informing public policy, these findings provide support for early behavioral interventions. Although there are no current best practice recommendations for programs to prevent or decrease obesity, a recent systematic review of the literature defined three primary components of such programs. Programs should (1) focus on prevention rather than intervention, (2) be implemented during the preschool years, and (3) include a component focused on parental involvement (as researchers often note that attendance is unsatisfactory due to parental time restrictions) [6, 25]. These three components provide further support for the use of preschool facilities for intervention purposes, as interventions provided within the context of preschools enable researchers to focus on prevention and do not require additional parent time.

While few targeted prevention programs have been designed for preschoolers, one program has been shown to effectively prevent weight gain in this population. The "Hip-Hop to Health" program was designed for Head Start preschoolers and includes a nutrition education and physical activity component. Results from preliminary and followup studies indicate that preschoolers participating in this program had smaller increases in BMI than peers who did not participate in this program $[26,27]$.

It is important to note that, while the results of this study indicate that preschool attendance was related to increased weight status, there are several advantages of preschool. Specifically, additional research with this database indicated that children who attended preschool were better prepared for kindergarten, as measured by performance on a state-mandated school readiness test. This finding is consistent with numerous studies which have documented the cognitive and academic gains made by children who attended preschool [28].

There are several limitations to the current study. First, given the correlational nature of our data, it is not possible to infer causal results. Future studies should use longitudinal data to further examine the relationship between preschool attendance and weight while controlling for weight at preschool entry. Second, we were not able to examine the amount of time spent in preschool. Examination of this variable in future studies could further our understanding of the relationship between preschool attendance and weight. Third, the examination of the specific mechanisms including environmental or cultural factors that may link preschool attendance and weight was beyond the scope of this study. Ideally, future studies should use a much more precise measure of income as well as more nationally representative samples to further our understanding of the roles of race/ethnicity, income, and other demographic variables in childhood obesity. Similarly, we were not able to measure all potential confounding variables including maternal weight. As the literature suggests that variables such as maternal weight are highly related to child weight status, future research should incorporate these variables to allow us to better understand childhood obesity [29]. Finally, our results indicated a relationship between preschool and obesity as well as preschool and income, but the relationship between obesity and income was not supported. Given these findings, the numerous studies linking income and obesity, and our use of a proxy variable to examine family income, the possibility of a type 2 error should be considered. In light of these limitations, there are a number of opportunities for future research including examination of specific mechanisms that may account for the relationship between weight and preschool attendance using longitudinal data.

\section{Summary}

In summary, this study contributes to the current literature by describing the relationship between preschool attendance and overweight and obesity in an at-risk population. To our knowledge, this study is only the second to examine this relationship and the first to focus specifically on an urban public school population. Findings indicate that children attending public preschools may be at an increased risk for overweight and obesity at kindergarten entry, and illustrate the importance of additional public policy work to enact legislation surrounding the nutritional environment and physical activity requirements of the preschool setting. Further, these findings underscore the conclusions of previous research indicating that implementing prevention and intervention programs in the preschool setting should be considered as a critical next step in reducing the potential for long-term obesity.

\section{References}

[1] C. L. Ogden, M. D. Carroll, L. R. Curtin, M. A. McDowell, C. J. Tabak, and K. M. Flegal, "Prevalence of overweight and obesity in the United States, 1999-2004," Journal of the American Medical Association, vol. 295, no. 13, pp. 1549-1555, 2006.

[2] S. R. Daniels, "The consequences of childhood overweight and obesity," Future of Children, vol. 16, no. 1, pp. 47-67, 2006.

[3] M. Stradmeijer, J. Bosch, W. Koops, and J. Seidell, "Family functioning and psychosocial adjustment in overweight youngsters," International Journal of Eating Disorders, vol. 27, no. 1, pp. 110-114, 2000.

[4] M. H. Zeller and A. C. Modi, "Predictors of health-related quality of life in obese youth," Obesity, vol. 14, no. 1, pp. 122130, 2006.

[5] J. B. Schwimmer, T. M. Burwinkle, and J. W. Varni, "Healthrelated quality of life of severely obese children and adolescents," Journal of the American Medical Association, vol. 289, no. 14, pp. 1813-1819, 2003.

[6] J. D. Skinner, B. R. Carruth, W. Bounds, P. Ziegler, and K. Reidy, "Do food-related experiences in the first 2 years of life predict dietary variety in school-aged children?" Journal of Nutrition Education and Behavior, vol. 34, no. 6, pp. 310-315, 2002.

[7] L. L. Birch and J. O. Fisher, "Development of eating behaviors among children and adolescents," Pediatrics, vol. 101, no. 3, pp. 539-549, 1998. 
[8] S. G. Trost, J. R. Sirard, M. Dowda, K. A. Pfeiffer, and R. R. Pate, "Physical activity in overweight and nonoverweight preschool children," International Journal of Obesity and Related Metabolic Disorders, vol. 27, no. 7, pp. 834-839, 2003.

[9] S. Sherburne-Hawkins and K. Law, "A review of risk factors for overweight in prschool children: a policy perspective," International Journal of Pediatric Obesity, vol. 1, pp. 195-209, 2006.

[10] W. S. Barnett and D. J. Yarosz, "Who goes to preschool and why does it matter?" Preschool Policy Brief, vol. 15, pp. 1-12, 2007.

[11] J. C. Lumeng, K. Gannon, D. Appugliese, H. J. Cabral, and B. Zuckerman, "Preschool child care and risk of overweight in 6to 12-year-old children," International Journal of Obesity, vol. 29, no. 1, pp. 60-66, 2005.

[12] E. J. Maher, G. Li, L. Carter, and D. B. Johnson, "Preschool child care participation and obesity at the start of kindergarten," Pediatrics, vol. 122, no. 2, pp. 322-330, 2008.

[13] Centers for Disease Control, "CDC Growth Charts," 2009, http://www.cdc.gov/GrowthCharts/.

[14] F. W. Danner, "A national longitudinal study of the association between hours of TV viewing and the trajectory of BMI growth among US children," Journal of Pediatric Psychology, vol. 33, no. 10, pp. 1100-1107, 2008.

[15] M. D. Hanson and E. Chen, "Socioeconomic status, race, and body mass index: the mediating role of physical activity and sedentary behaviors during adolescence," Journal of Pediatric Psychology, vol. 32, no. 3, pp. 250-259, 2007.

[16] P. Gordon-Larsen, M. C. Nelson, P. Page, and B. M. Popkin, "Inequality in the built environment underlies key health disparities in physical activity and obesity," Pediatrics, vol. 117, no. 2, pp. 417-424, 2006.

[17] B. W. Timmons, P.-J. Naylor, and K. A. Pfeiffer, "Physical activity for preschool children-how much and how?" Applied Physiology, Nutrition and Metabolism, vol. 32, pp. S122-S134, 2007.

[18] J. Worobey, H. S. Worobey, and A. L. Adler, "Diet, activity and BMI in preschool-aged children: differences across settings," Ecology of Food and Nutrition, vol. 44, no. 6, pp. 455-466, 2005.

[19] M. K. Fox, A. H. Dodd, A. Wilson, and P. M. Gleason, "Associations between school food environment and practices and body mass index of US public school children," Journal of the American Dietetic Association, vol. 109, no. 2, pp. S108S117, 2009.

[20] M. Story, "The Third School Nutrition Dietary Assessment Study: findings and policy implications for improving the health of US children," Journal of the American Dietetic Association, vol. 109, no. 2, pp. S7-S13, 2009.

[21] M. A. Clark and M. K. Fox, "'Nutritional quality of the diets of US public school children and the role of the school meal programs," Journal of the American Dietetic Association, vol. 109, no. 2, pp. S44-S56, 2009.

[22] "Ohio Regulations: National Resource Center for Health and Safety in Child Care Web Site," January 2009, http://nrckids.org/STATES/OH/ChildCareManual.pdf.

[23] S. Fleischhacker, K. L. Cason, and C. Achterberg, "“You had peas today?": a pilot study comparing a head start child-care center's menu with the actual food served," Journal of the American Dietetic Association, vol. 106, no. 2, pp. 277-280, 2006.

[24] American Dietetic Association, "Position of the American Dietetic Association: penchmarks for nutrition programs in child care settings," Journal of the American Dietetic Association, vol. 105, no. 2, pp. 979-986, 2005.
[25] M. Moya, "An update in prevention and treatment of pediatric obesity," World Journal of Pediatrics, vol. 4, no. 3, pp. 173-185, 2008.

[26] M. L. Fitzgibbon, M. R. Stolley, L. Schiffer, et al., "Hip-Hop to Health Jr. for Latino preschool children," Obesity, vol. 14, no. 9, pp. 1616-1625, 2006.

[27] M. L. Fitzgibbon, M. R. Stolley, L. Schiffer, L. Van Horn, K. KauferChristoffel, and A. Dyer, "Two-year follow-up results for Hip-Hop to Health Jr.: a randomized controlled trial for overweight prevention in preschool minority children," Journal of Pediatrics, vol. 146, no. 5, pp. 618-625, 2005.

[28] A. J. Reynolds, J. A. Temple, S.-R. Ou, et al., "Effects of a school-based, early childhood intervention on adult health and well-being: a 19-year follow-up of low-income families," Archives of Pediatrics and Adolescent Medicine, vol. 161, no. 8, pp. 730-739, 2007.

[29] C. Semmler, J. Ashcroft, C. H. M. Van Jaarsveld, S. Carnell, and J. Wardle, "Development of overweight in children in relation to parental weight and socioeconomic status," Obesity, vol. 17, no. 4, pp. 814-820, 2009. 


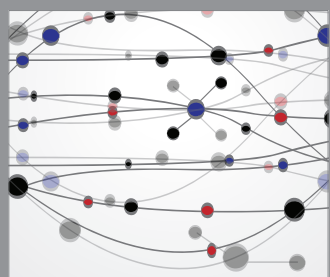

The Scientific World Journal
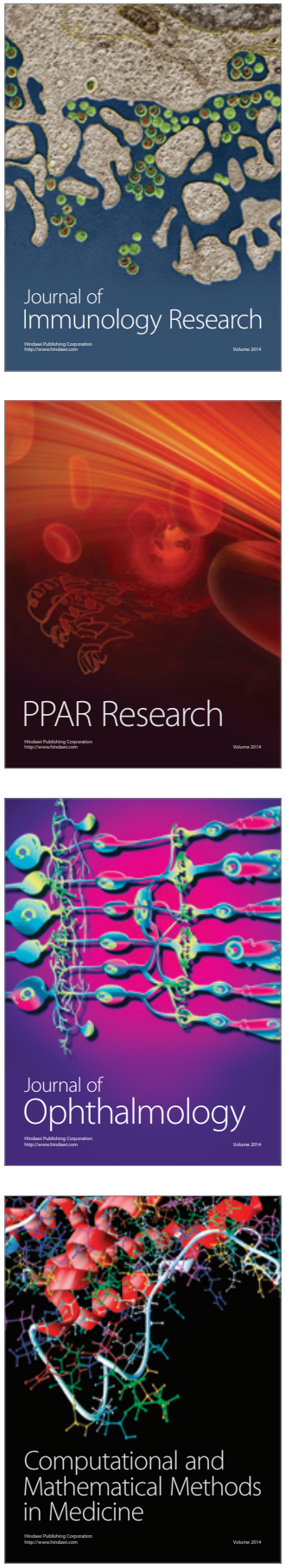

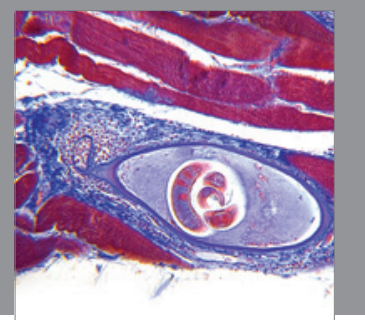

Gastroenterology

Research and Practice
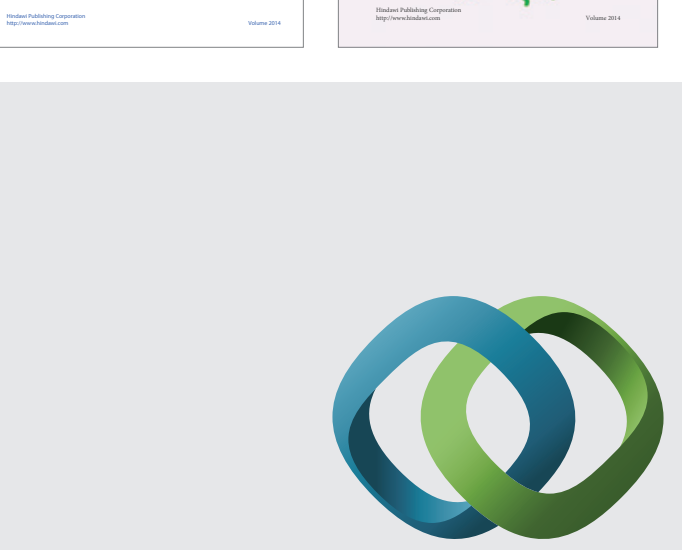

\section{Hindawi}

Submit your manuscripts at

http://www.hindawi.com
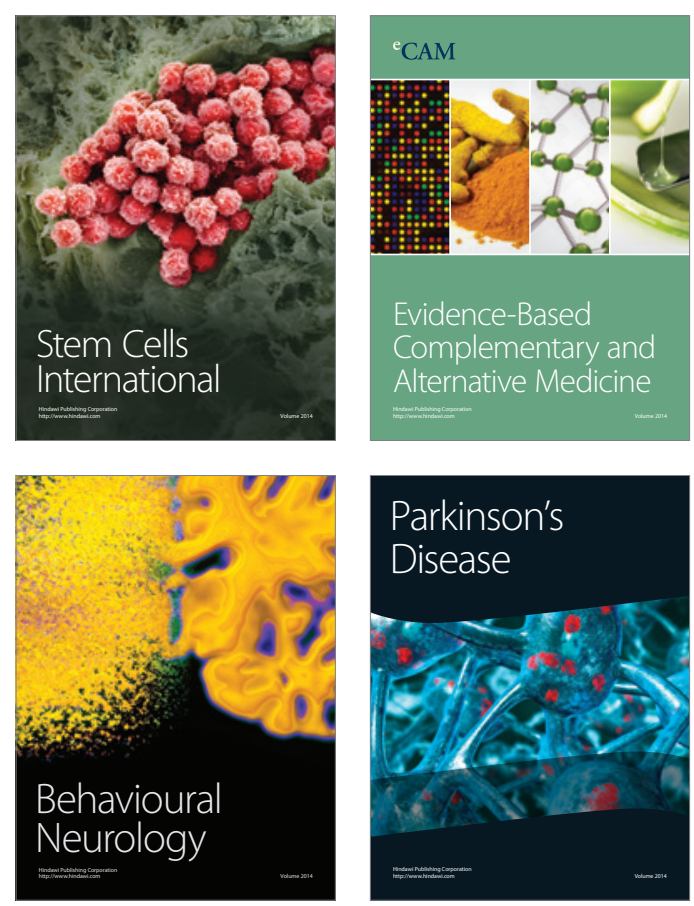

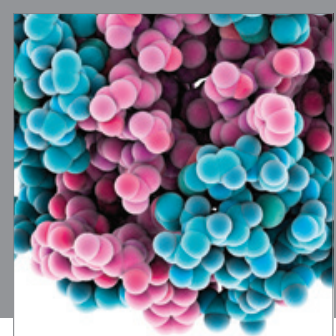

Journal of
Diabetes Research

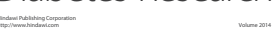

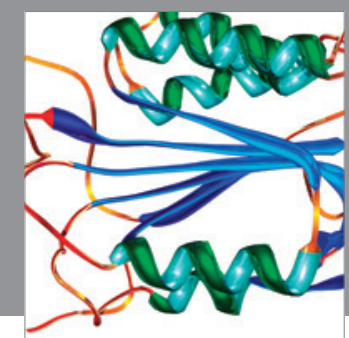

Disease Markers
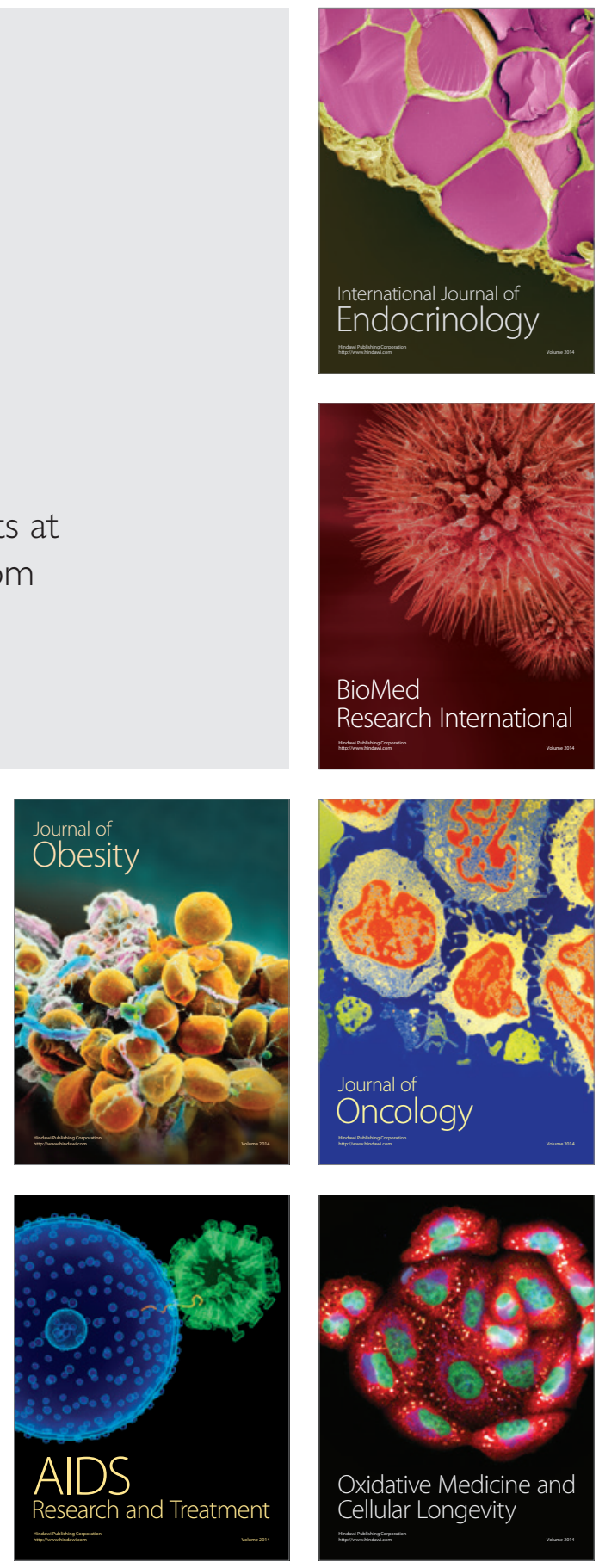